\title{
A gramática na década de 70: apropriação, autoria e posição-sujeito*
}

\author{
Maria Iraci Sousa Costa**
}

\begin{abstract}
Resumo: Nossa proposta de trabalho, inscrita no projeto de iniciação científica intitulado História das Ideias Linguísticas no Sul: estudo das ideias e organização da memória dos anos 80 a 2000, é parte da investigação que vimos desenvolvendo sobre a Moderna Gramática Brasileira (1976), de Celso Pedro Luft. Filiando-nos à Análise de Discurso de linha francesa e à História das Ideias Linguísticas, mobilizamos as noções de sujeito, posição-sujeito e autoria para investigarmos como o gramático Celso Pedro Luft apropria-se de outros saberes metalinguísticos diante da emergência da Linguística nos cursos de Letras do Rio Grande do Sul, na década de 70.
\end{abstract}

Palavras-chave: Autoria; Gramática; Linguística.

\section{Uma relação histórica}

Uma vez constituída a nação brasileira, a língua falada no Brasil começa a ser questionada por intelectuais brasileiros. Conforme Guimarães (2004), essa movimentação de ideias é parte de uma reação contra a "recolonização", que tem início a partir da segunda metade do século XIX. A maior parte dos estudos realizados anteriormente ao início da produção de instrumentos linguísticos no Brasil, que, de acordo com Orlandi (2002), começaram a partir da segunda metade do século XIX, consistia em apontar as diferenças do português falado no Brasil e o falado em Portugal, bem como suas respectivas escritas. De acordo com Teyssier (1997), logo após a independência, a questão da língua portuguesa no Brasil preocupou particularmente os escritores e os filólogos. Românticos bem como modernistas reivindicavam a autenticidade da língua brasileira, mas, ainda segundo Teyssier (Ibid.), suas investidas não tinham caráter científico, baseavam-se apenas em aspectos, como por exemplo, a adoção de um certo vocabulário, o uso brasileiro em matéria de colocação de pronomes, o emprego do verbo ter impessoal, casos particulares de regência e de concordância, etc. Nota-se que essa discussão em torno da particularidade do português brasileiro

\footnotetext{
* Trabalho de iniciação científica (Bolsa CNPq/Balcão) elaborado durante o Curso de Graduação em Letras, sob orientação da Prof. ${ }^{a}$ Dr. Amanda Eloina Scherer, e vinculado ao projeto de pesquisa atual intitulado De Gramática Resumida a Moderna Gramática Brasileira: deslocamentos e efeitos de sentidos.

** Mestranda em Letras - Estudos Linguísticos, no Programa de Pós-Graduação em Letras da UFSM, sob orientação da Prof. ${ }^{a}$ Dr. Amanda Eloina Scherer. E-mail: iraciscosta@yahoo.com.br
} 
sugere que o português seja a única língua falada no Brasil, ótica essa construída histórica e ideologicamente. A política linguística do Estado sempre foi reduzir o número de línguas e, por isso, silencia-se o fato de que no Brasil são faladas inúmeras línguas. Entretanto, para os gramáticos, aceitar esse vasto repertório de línguas e suas respectivas variações tornaria impossível a produção de gramáticas. Não se pode negar a importância da gramática em relação à unidade da língua, mas pensar o português brasileiro apenas dessa perspectiva é aceitar o mito de que o Brasil é um país monolíngue, o que de fato nunca foi, não é e tampouco será.

De uma perspectiva linguística, é consenso a ideia de que o território brasileiro é um espaço multilíngue, no sentido de que, além do português, são faladas uma diversidade de línguas indígenas, de línguas de imigração e de línguas de fronteira e, é claro, as suas respectivas variações. Mas, pensando somente a variação do português no Brasil, entre as décadas de 30 e 40 foi cogitada uma nova denominação para essa língua. De acordo com Dias (2001), entre essas duas décadas houve três projetos legislativos que propunham a denominação "língua brasileira" como substituição para a denominação língua portuguesa, contudo ao final foi decretado que a língua falada no Brasil deveria ser designada "Língua Portuguesa".

Desse modo, pode-se dizer que a) a denominação "língua brasileira" não tem legitimidade alguma frente ao Estado; b) essa denominação implica não mais a unidade entre o português de Portugal e o português do Brasil, mas a variedade no português do Brasil; e c) essa discussão levanta divergências entre gramáticos e linguistas. Desse modo, iniciaremos nossa leitura pensando a denominação "Moderna Gramática Brasileira”, refletindo sobre a contradição que essa denominação estabelece entre a Gramática e a Linguística e, a partir do movimento de autoria e posição-sujeito, investigar como se dá a apropriação dos saberes do linguista pelo gramático Celso Pedro Luft.

\section{Um gesto teórico}

O sujeito, em uma perspectiva discursiva, é um sujeito social que não apresenta características individualizadoras e só existe a partir da relação com o outro. De acordo com Pêcheux (1997), os indivíduos são ‘interpelados’ em sujeitos-falantes pela identificação com as formações discursivas, como se o eu que escuta se colocasse no lugar de quem fala, assumindo a forma-sujeito de tal formação discursiva. Identificando-se com uma determinada formação discursiva, o sujeito toma o dizer do outro como parte constitutiva do seu dizer sob a forma o interdiscurso.

No entanto, o sujeito do discurso é dividido, isto é, pode assumir diferentes posições dentro da formação discursiva em que se inscreve. Essas posições são denominadas por Pêcheux (Ibid.) de modalidades. Na primeira 
modalidade, o sujeito se identifica plenamente com a forma-sujeito da formação discursiva, a quem Pêcheux chama de bom sujeito. Na segunda modalidade, o sujeito se contraidentifica com a forma-sujeito da formação discursiva, abrindo espaço para a diferença e para a dúvida, mas não rompe com a formação discursiva em que se inscreve. A esse sujeito Pêcheux denominou mau sujeito. Há ainda uma terceira modalidade em que o sujeito se desidentifica com a forma-sujeito, deslocando-se para uma outra formação discursiva. Segundo Pêcheux (Ibid., p.217), essa desidentificação está atrelada ao "processo subjetivo de apropriação dos conceitos científicos e de identificação com as organizações políticas de tipo novo", ou seja, há uma necessidade de desidentificação, mesmo que imaginária, para que se efetue a apropriação subjetiva dos conhecimentos, de modo que para o sujeito se apropriar de um determinado conhecimento, é necessário se reportar para a formação discursiva a que pertence esse saber.

Já a autoria não deixa de estar relacionada à apropriação, pois entendemos por autoria “o gesto de se colocar na 'origem' do seu dizer e tomá-lo ilusoriamente como 'seu', tornando-se identificável e responsável pelo seu dizer" (Orlandi, 1993). No caso da gramática, o decreto da Nomenclatura Gramatical Brasileira (NGB) em 1958, pelo Estado, tomou do gramático a sua forma de autoria, atribuindo-a aos linguistas, concebidos como produtores de conhecimento científico sobre a língua (cf. Orlandi, 2002). Desse modo, entendemos que, ao apropriar-se do saber do linguista, o gramático da Moderna Gramática Brasileira deixa de ser mais um repetidor, explicador (cf. Baldini, 1998) para colocar-se na origem de um novo saber ao tomá-lo imaginariamente como seu.

\section{Um gesto analítico}

A Moderna Gramática Brasileira (MGB) seria a terceira edição da Gramática Resumida (GR) de Celso Pedro Luft. A primeira edição da GR foi publicada em 1960, logo após a instauração da NGB, com o objetivo de explicar a aplicação da nova nomenclatura. A segunda edição da GR, publicada em 1963, passou por uma série de acréscimos e correções, enquanto a terceira, publicada em 1976, já estava tão distante da primeira que recebeu um outro nome: Moderna Gramática Brasileira. Assim, a nova gramática deixou de ser a terceira edição da Gramática Resumida para ser a primeira da Moderna Gramática Brasileira. A razão de tal distanciamento é que Celso Pedro Luft já não se atém somente à NGB, ele não só a contesta como também adota uma série de termos pertencentes à área do linguista.

$O$ corpus da nossa pesquisa, a MGB, foi publicado numa época em que a disciplinarização da Linguística no Brasil estava provocando um impacto progressivo sobre a gramática normativa, de modo que, de um lado, tinha-se 
um novo pensamento linguístico e, de outro, a antiga e clássica concepção da gramática como arte de ensinar a falar e escrever corretamente (Guimarães, 2004). Essa polaridade fez com que muitos gramáticos passassem a contestar a gramática normativa e a forma como ela estava sendo utilizada em sala de aula, sendo a principal contestação o modo impositivo e dogmático de tradição lusitana. Desse modo, entendemos que a designação Moderna Gramática Brasileira aponta para o possível posicionamento do gramático Luft em relação ao uso da gramática em sala de aula. Assim, nosso primeiro recorte, que será denominado sequência discursiva (doravante SD), refere-se sobre ao posicionamento do gramático em relação à colocação pronominal nas gramáticas brasileiras, uma vez que defende a insubordinação às regras lusitanas em função da sua não aplicação à realidade brasileira:

SD1 - Não faz nenhum sentido Gramáticas brasileiras condenarem a colocação brasileira dos pronomes: é como Gramática de Portugal condenar colocações lusitanas (qué-lo, fá-lo, trar-to-ei, dou-ta). À Gramática cabe registrar - e não condenar - usos de linguagem (MGB, p. 20).

Em SD1, o gramático define com qual formação discursiva ele se identifica, que é a gramático brasileiro, bem como estabelece o que pode e deve ser dito. Assim, condenar os usos da linguagem situa-se fora daquilo que pode e deve ser dito. Esse gramático se submete sob a forma do "sujeito ideológico" (Pêcheux, 1997), aquele que veicula "o que todo mundo sabe" como norma identificadora. A identificação se dá a partir de um espelhamento, no qual o sujeito projeta no outro a imagem que tem de si mesmo. O sujeito se identifica com o outro e consigo mesmo simultaneamente. Uma vez já-sujeito, ele se esquece das determinações que o colocaram no lugar que ocupa, de modo que a identificação, fundadora da unidade (imaginária) do sujeito, baseiase em elementos do interdiscurso que são reinscritos no discurso do próprio sujeito. Historicamente, a ideia de correção, de imposição de regras está ligada à gramática. Somente com a Linguística, a ideia de que a língua só pode ser classificada como certo e errado é desestabilizada, e é nesse interdiscurso que aparece o dizer do linguista.

Porém, segundo Pêcheux (1990), não há identificação plenamente bem sucedida, e aquilo que não pode e não deve ser dito é uma possibilidade latente. Desse modo, o sujeito pode não concordar com tudo aquilo que é dito na formação discursiva com a qual se identifica, contraidentificando-se com a posição-sujeito dominante. É o que se observa na seguinte sequência discursiva:

SD2 - A sintaxe fazem vinte anos, haviam dez meses, com a pessoalização desses verbos, é considerada de nível baixo, vulgar (MGB, p.27). 
Tem-se, em SD2, um juízo de valor que, uma vez enunciado que "à gramática cabe registrar e não condenar os usos da linguagem", desestabiliza o discurso desse sujeito, contradizendo o que foi dito antes. Se na sequência discursiva anterior ele identificava-se plenamente com a posição-sujeito dominante, agora, nessa sequência discursiva, ele se contraidentifica. No entanto, entendemos que essa contraidentificação é parcial, uma vez que se tem um "apagamento" do sujeito: é considerada por quem? Essa estratégia sugere um distanciamento desse gramático como se ele estivesse se descomprometendo e apenas reproduzindo esse discurso. Desse modo, podese dizer que há uma dupla contra-identificação: a primeira com a posiçãosujeito dominante da formação discursiva com a qual o sujeito gramático brasileiro se identifica e, a segunda, com a tradição gramatical que contempla como certa apenas a sintaxe de grandes textos literários.

\section{Considerações finais}

A partir da nossa análise, consideramos que o movimento de autoria corresponde a um gesto de apropriação de conhecimentos do linguista, pois este é quem detém o saber científico. Se na Gramática Resumida não havia movimento de autoria em consequência do decreto da NGB, na Moderna Gramática Brasileira esse movimento é retomado. No entanto, ao tomar o discurso do linguista como seu, esse gramático constrói um discurso que se opõe ao seu discurso de gramático, pois adota perspectivas diferentes que contradizem umas as outras. Ao retomar o movimento de autoria, o gramático da Moderna Gramática Brasileira acaba exercendo uma função-sujeito que o coloca diretamente ligado ao social, seu discurso se inscreve num confronto entre o simbólico e o político, entre a Linguística e a Gramática e, portanto, seu discurso se torna polêmico e contraditório.

\section{Referências}

BALDINI, Lauro J. S. A nomenclatura gramatical brasileira interpretada, definida, comentada e exemplificada. 1998. Dissertação (Área de Concentração: Análise do Discurso) - Instituto de Estudos da Linguagem, Universidade Estadual de Campinas, Campinas.

DIAS, Luiz Francisco. O nome da língua no Brasil: uma questão polêmica. In.: ORLANDI, Eni P. (org.). História das idéias lingüísticas: construção do saber metalingüístico e constituição da língua nacional. Campinas: Pontes; Cáceres: Unemat, 2001, p. $185-198$.

GUIMARÃES, Eduardo. História da semântica: sujeito, sentido e gramática no Brasil. Campinas, São Paulo: Pontes, 2004.

LUFT, Celso Pedro. Moderna gramática brasileira. Rio de Janeiro: Globo, 1976. 
ORLANDI, Eni P.. Língua e conhecimento lingüístico: para uma história das idéias no Brasil. São Paulo: Cortez, 2002.

. Discurso e leitura. São Paulo: Cortez; Campinas: Unicamp, 1993.

PÊCHEUX, Michel. Semântica e discurso: uma crítica à afirmação do óbvio. Traduzido por E. P. Orlandi. 3.ed. Campinas: Unicamp, 1997.

TEYSSIER, Paul. História da língua portuguesa. Traduzido por C. Cunha. São Paulo: Martins Fontes, 1997. 